\title{
Integration and Synergy Generation in Cross Border Acquisitions: A Case Study of Business Failure and Success 'Made in Japan'
}

\author{
Shigeru Matsumoto ${ }^{1} \&$ Keith Jackson ${ }^{1,2}$ \\ ${ }^{1}$ Graduate School of Business, Doshisha University, Kyoto, Japan \\ ${ }^{2}$ SOAS, University of London, UK \\ Correspondence: Shigeru Matsumoto, Graduate School of Business, Doshisha University, Kyoto, Japan.
}

Received: June 30, 2017

doi:10.5539/ibr.v10n9p122
Accepted: August 7,2017

Online Published: August 16, 2017

URL: https://doi.org/10.5539/ibr.v10n9p122

\begin{abstract}
This article seeks to advance international business researcher and practitioner insights into processes of cross-border mergers and acquisitions. Specifically, this article highlights the extent to which processes of strategic integration might impact positively and / or negati vely on the long term business performance of the newly formed firm during the post-acquisition period - a measure of performance we refer to here as 'synergy'. In methodological terms, this article develops a mixed-method case study approach, generating, analysing and interpreting empirical data designed to illustrate processes of strategic integration implemented by senior managers at a Japanese firm, Nippon Sheet Glass (NSG), after its acquisition of a UK firm, Pilkington. The case study is longitudinal, drawing on quantitative and qualitative data gathered and analysed between 2006 and 2017. Applying a combination of event study methodology to an iterative analysis of business performance data along with coded analysis of data from in-depth interviews with key stakeholders, this article explores the extent to which strategic integration can both 'fail' in terms of achieving synergy and - for a number of generalizable reasons proposed in this article - ultimately 'succeed': for example, in cases where the acquiring and acquired firms attempt to integrate their human resource management systems while benefitting from investments of 'patient' capital, which (we propose) might be a distinctive feature of cross-border acquisitions sourced in Japan.
\end{abstract}

Keywords: case study, cross-border acquisition; Japan, strategic integration, synergy

\section{Introduction}

In contexts for international business (IB) research and practice there appears to be an expectation that international or cross border M\&As are more likely to result in failure than in success (Cartwright \& Schenberg, 2006; Bartlett \& Beamish, 2014). The case study presented in this article illustrates both poles of this performance continuum: namely, a relative and perhaps predictable IB 'failure' that, most recently, appears to have become a notable IB 'success'. As such, we believe the case study presented and discussed subsequently in this article can inform and indeed advance IB research and practice with insights into processes of cross-border mergers and acquisitions.

The context for the case study presented and discussed here is given by current and emerging flows of foreign direct investment that, in turn, increasingly inform developments in the research and practice of IB. In general terms, foreign direct investment (FDI) can be defined as both a channel and a form of investment that companies use to acquire assets abroad (Ietto-Gillies, 2012). As illustrated in this article, flows of outward-bound FDI from Japan continue to target overseas or cross-border acquisitions. In 2016, the total value of Japan-sourced acquisitions reached JPY 10.4 trillion (USD 100 billion), three times higher than the total value of domestic transactions within Japan (UNCTAD, 2017). The total number of recorded cross-border acquisitions was 635 - a record high and representing an increase 13.4 per cent increase from 2015 (Nikkei, 2015).

As a specific form of FDI, the United Nations Conference on Trade and Development (UNCTAD) defines mergers and acquisitions (M\&As) as 'situations where there is a legal operation between two or more enterprises whereby firms legally unify assets formerly subject to separate control' (UNCTAD, 2017). In a seminal work in the field of IB research, Hymer (1960) emphasises the factor of 'control' when making foreign or overseas investments and, by extension, control over any return on these investments along with subsequent distribution of added value that investors and other key stakeholders calculate and / or perceive to have been generated by the 
investment. The emphasis given to 'control' becomes strategically relevant when firm or companies seeking assets abroad identify and consider the option of either 'merging' with a foreign company - for example, offering some legal and / or strategic share of control - or of 'acquiring' a foreign company, where the structure of ownership allows for a greater degree of strategic control over the newly formed (post-acquisition) company. The extent to which control might be interpreted differently according to factors such as source of investment (Japan), size of organisation (NSG in relation to Pilkington) and implied / expressed 'strategic intent' (Pucik, Björkman, Evans \& Stahl, 2011) are subject to critical discussion in this article.

Overall, this article highlights the extent to which processes of strategic integration might impact positively and / or negatively on the long-term business performance or synergistic achievements of the newly formed firm during the post-acquisition period. Finally, the article explores the extent to which the evidence for synergy being achieved (or not) through targeted processes of strategic integration in the NSG-Pilkington case might be generalised to other contexts for IB practice and research. There are limitations of this single case study approaches but this paper contributes to identify insight of cross border acquisitions. We plan to conduct more comparative data and transaction case analysis between Europe and Japan in our future research in order to provide more details to measure of achieving cross border synergy.

\section{Literature Review}

In order to develop a conceptual basis for the case study forming the core of this article, and by extension for the choices of research methods that we combined to produce the case study, we offer now a brief review of literature relevant to the two core IB concepts highlighted and linked in this article: namely, 'synergy' and 'strategic integration' in contexts for cross-border acquisitions sourced in Japan.

\subsection{Synergy}

In contexts for FDI in the form of company acquisitions, a shorthand equation for 'synergy' as a strategic aspiration or intent can be expressed as ' $1+1=3$ ', whereby ' 1 ' (value of the acquiring company) plus ' 1 ' (value of the acquired company) are calculated eventually to equal ' 3 ' or more (Marks \& Mirvis, 1998). Goold and Campbell (1998) identify six company-specific assets that might be 'synergized' post-acquisition: 'know-how' such as local market knowledge; 'tangible resources' such as production equipment and distribution facilities; 'negotiating power' such as leverage in negotiating delivery terms with suppliers; 'coordinated strategies', whereby each company might reduce risk by becoming market allies rather than rivals; 'vertical integration', whereby the flow of products or services across a company's 'value chain' (Porter, 1985) might be combined and thereby reduce costs and improve efficiency. The sixth potential source of synergy proposed by Goold and Campbell (1998) is 'combined business creation', whereby the newly formed post-acquisition company is able to combine sufficient resources towards forming or developing new businesses - or, as illustrated in the case study presented in this article, developing and expressing new ways of engaging in international business.

Drawing on Terjesen (2016) and on Bamford, Ernst and Fubini, (2004), measurable benefits from synergies between firms that form strategic alliances such as joint ventures (JVs) international joint ventures (IJVs) and (as discussed here) M\&As include:

\section{- Consolidation value derived from deep combination of existing businesses}

- Skills / knowledge transfer value derived from the transfer of some key skills and knowledge from one partner to the other partner

- Coordination value derived from leveraging the complementary capabilities of all participating partners

- New business value derived from combining existing capabilities to create new growth: for example, by developing position in existing or new markets.

Sirower (1997) defines 'synergy' as 'the increase in performance of the combined firm over what the two firms are already expected or required to accomplish as independent firms'. As we illustrate in this article, one major challenge facing managers engaged in negotiating cross-border alliances is identifying boundaries for strategic 'independence' as opposed (for example) to strategic control during processes of integrating two or more companies. Each entity requires the other in order (firstly) to survive and (subsequently) to remain competitive (Bartlett \& Beamish, 2014).

There are generally two types of approaches to generate increased performance or 'synergy' after acquisition: one targets economies-of-scale; the other economies-of-scope. Reducing operating costs by rationalizing duplicated plants, distribution channels, and/or back office operations is typical when leveraging economies-of-scale (Matsumoto, 2017). To illustrate, researching patterns of M\&A activities in the United States of America, Maksimovic, Phillips and Prabhala (2011) identified how 27 per cent of acquired plant was sold off and 19 per cent 
closed down within three years after the transaction; 30 per cent were sold and 27 per cent were closed within five years. Acquiring a company with similar profile and resource structures to the acquirer tends to target economies-of-scale. With this type of acquisition, acquires can receive efficiency gains and market power enhancements by achieving monopoly-like conditions. However, this type of acquisition is unlikely to create sustainable competitive advantages. For example, when Exxon acquired Mobil, the acquirer's already substantial market power was increased; howe ver, there is little evidence of added value beyond efficiency. On the other hand, acquiring firms with different but complementary resources provides the opportunity for significant amounts of value- creating synergy, although achieving it is challenging (Harrison. J., M. Hitt, R. Hoskinsson, \& D. Ireland (2001).

\subsection{Strategic Integration}

One common approach towards achieving post-acquisition synergy is to invest in processes of 'strategic integration'. Drawing on Burgelman (2001, 2005), these integration processes can be observed and described as patterns of management thinking and decision-making that, in sum, appear to represent a systematic and co-ordinated attempt by senior managers to combine and align resources and competencies from across business units in existing and (through acquisition) newly-formed companies: as we shall see, in the case of NSG's acquisition of Pilkington, the more 'globally minded' management styles of the acquired company were targeted for transfer back into the acquiring company. The synergy that might emerge over time as a measurable and / or perceptible return on investments in strategic integration can be identified in (for example) new and emergent combinations of resources such as capital, market reach, organisational knowledge and technology-based assets such as internationally co-ordinated and efficiently functioning IT systems. As we illustrate subsequently in our case study, synergy in terms of enhanced human capital / resources appears key towards sustaining any performance improvements gained: for example, an enhancement of competencies among core staff, including leadership and international business agility and effectiveness.

Re-invoking notions of strategic control in contexts for such acquisitions, the initiative for investing in processes of integration can be expected to lie with the acquiring company. Correspondingly, and echoing Porter (1996), a 'strategy' represents a systematic attempt by senior managers in a company to identify and define market opportunities and, consequently, to design, plan and implement a series of measures that should enable the company to establish and develop a 'unique and valuable' market position that, through the co-ordinated activities of the organisation and its key stakeholders, should render this position difficult for market rivals to imitate or surpass. In specific relation to Japanese organisations, an established strategic approach is to seek competitive and sustainable positions through forming and maintaining long-standing 'partnerships' or 'alliances', either though supplier / distributor agreements, joint ventures, mergers and occasionally through cross-border acquisitions (Jackson \& Matsumoto, 2016; Hemmert \& Jackson, 2016).

Among Japanese companies especially, this strategic orientation became the norm towards establishing positions in domestic markets and led to the formation of distinctive network structures such as keiretsu (Gerlach, 1992) - a strategic approach towards risk management and asset control that, as Gerlach argues, can be observed over time as evidence of a strategic paradigm or 'mind-set' common among senior Japanese managers and one that they subsequently carry over as a strategic expectation prior to extending their company's operations along with supply and distribution lines into overseas markets through the acquisition of non-Japanese assets (Matsumoto \& Mishina, 2016;Jackson \& Matsumoto, 2016). Before detailing the specific case of NSG's acquisition of Pilkington it is worthwhile expanding the temporal and geographical scope of this definition. For example, it is relevant to invoke processes generally referred to as 'globalisation' and purportedly serving to explain how and why multiand trans-national corporations (MNCs / TNCs) pursue strategic objectives such as achieving economies of scale and efficiency in processes of procurement, production and distribution (Bartlett \& Ghoshal, 1991). Emphasising the potential benefits of strategic integration in support of such strategies, conceptualisations of transfer and assimilation of knowledge from local markets might be assimilated or 'internalised' into the investing firm organisation such that its performance capacity could outstrip that of competing rivals and, perhaps, block their successful entry into emerging markets ( Dunning, 1980), either though single firm investments or, as the globalised business environment became more complex , through select alliances with one-time rivals (Dunning, 1997; Nohria \& Ghoshal, 1997; Ietto-Gillies, 2012).

With this range of 'global' strategic choices in mind, the literature discussing strategic integration highlight a number of specific choices, indicating (from a strategic management perspective) a mix of 'either /or' and 'both-and' emphases. To illustrate, scholars commonly distinguish between so-called 'forward' and 'backward' integration investments: in the former case, existing products and quality standards operated by an acquiring firm might be distributed directly 'forwards' to new customers in order to reduce time lags of bringing upgraded quality 
and (possibly) rebranded products to market; alternatively, the acquiring firm might delay market penetration in order to ascertain and communicate market-specific information 'backwards' into existing production processes the new target customer expectations and as a consequence adjust the quality and (possibly) price of their products for distribution in newly accessed market (Casson, 1982). A further mix of strategic integration choices appear to senior managers, who frame their company's response to globalisation using transaction cost theory and related approaches. Here the directional emphasis of integration investments can be identified as 'horizontal', whereby firms seek to control the procurement, production and distribution costs underlying their business performance by owning the business units that provide theirs value-adding activities. For contrast, so-called ' vertical' integration investments target control of markets consistent with a firm's existing products and cost structures: for example, by establishing or maintaining monopolies of supply in response to demand and / or using the threat of penalties to distributors who might be inclined to supply local markets on a more independent cost-structure and demand-supply basis (Caves, 1982, 1996). Such iterations of internationalisation theory in response to the purported 'globalisation' of business environments remain tentative and open to critical conjecture, and not least with a view to the rapid advances in communication and supply chain technologies (Ietto-Gillies, 2012). Nonetheless, they appear in essence to remain influential in international business research and, by extension, in practices informing international management education: for example, in the design and teaching of business case studies. As a consequence, these sources of influence appear to further feed the 'internal' versus 'external' control mind-set of managers: to illustrate, by bestowing further credibility to mantras linking 'measure - control - manage' and which arguably continue to lead senior managers across international borders to assume that 'if we acquire the assets then we control the assets and as a consequence can effectively manage the risks specific to taking exposed ownership (post-acquisition) positions across rapidly evolving global markets' (Mintzberg, 2005).Past research shows that similarity across two business offers acquires the potential for improved profitability through high integration (Zaheer, Castaner \& Souder, 2011). The specific benefits from integrating similar business - that is, targeting economies-of-scale benefits - are gained by eliminating of redundant or duplicated activities and by sharing or transferring resources across the combined company (Capron, 1999). On the other hand, (Datta \& Grant, 1990) find that "lower levels of autonomy can be expected" in acquisitions featuring similarity. The reason is that giving autonomy to similar target managers tends to resist the changes required by consolidation such as loss of resources under their control and thus power and prestige. In our case study, we detail how senior managers at NSG have tried to integrate Pilkington business and human resource management systems along with leadership thinking in the post-acquisition phase, initially without much apparent success but, ultimately, with such evident success that shareholders who have waited patiently over years for a real financial return on their investments are beginning to reap substantial gains.

\subsection{Acquisitions Sourced in Japan}

In this article we emphasise M\&A activity sourced in Japan as 'cross-border'. This is because of the distinctive geographical and institutional contexts for the development of Japanese business practices and management styles (Jackson \& Matsumoto, 2016; Jackson, 2016). Indeed, it is possible to argue that the relative success and as we discuss consequently - failure of cross-border investments sourced in Japan might be traced back to the distinctive patterns of institutional embeddedness evident in the decisions made by senior managers in Japanese companies when compared to their Western and East Asian counterparts (Hemmert \& Jackson, 2016; Jackson \& Matsumoto, 2016).

Correspondingly, one important factor that gives context to the case study presented in this article is that company-company acquisitions in Japanese domestic markets are and remain - by international comparisons relatively few. According to Sugiyama (2013), during the industrial and economic 'boom' years of the 1980s to the 1990s Japanese companies tended to view the acquisition of other Japanese companies as a strategic opportunity to improve their speed of technology development and innovation, assuming that for cultural, structural or other company-specific resource reasons the existing 'in-house' capabilities appeared lacking. Correspondingly, large-scale M\&A activities in Japan have tended to be concentrated in technology-based and research-intensive industries and sectors within Japan: for example, the Konica Minolta (2003) merger in precision electronics and the Daiichi-Sankyo (2005) in pharmaceuticals. Another sector worthy of mention here is the retail sector, notably in cases where department stores and carriers of domestic and (today) international brand names merge in order to respond to sluggish consumer markets. Examples include the 2008 merger between Mitsukoshi Department Store (founded in 1673) and Isetan (founded in 1886).

This traditional and (by global comparison) markedly incremental approach to acquisitions in domestic markets in Japan appears to extend to overseas markets for M\&A activities: for example, Takeda bought its international joint venture (IJV) with Abbot Laboratories in 2008. Conversely, the few examples of inward FDI to Japan in the 
form of M\&As indicate similar patterns of flow: for example, in 2014 Roche, a Swiss pharmaceutical company, developed on a previously established investment and a controlling stake in Chugai (Japan), thereby making headlines in the business media as one of the smoothest and most enduringly successful cross-border acquisitions (Herbes, 2016). Echoing Japan-specific research by Pucik (2008), the Roche-Chugai acquisition remains a relatively rare example of cross-border acquisition success in large part because each side shared a sense of urgency in creating and communicating a shared vision and furthermore by maintaining the positive momentum that initial negotiations towards some form of cross-border business alliance and collaboration had heralded.

As highlighted previously, one commonly applied measure of positive business performance during the post-acquisition phase is 'synergy' Echoing Goold and Campbell (1998), the term 'synergy' derives from a Greek word synergos, which can be rendered in English as 'working together'. In Japanese, the term 'synergy' commonly appears as シナジー (shi-nah-djee). In both English and Japanese 'synergy' explains how formerly separate entities can combine and function together such that they create more value to and for themselves in comparison to when each entity functioned independently. In general business terms, an acquiring entity pays a premium for the control stake it invests in a target entity in order to create future value by combining two operations. To illustrate, when Renault invested in Nissan in 1999 and gradually turned Nissan`s business performance around, senior Renault managers - under the leadership of Carlos Ghosn - emphasized that one major success factor would be the synergy they created by combining purchasing and product development operations (Nissan, 2016).

In terms specific to Japan, 'strategic integration' describes a managed and systematic process whereby two or more companies by design and intent become 'bound' to each other (Pucik et. al., 2011). In this sense, the context for attempting to achieve synergies might be conceptualised a 'newly formed company', implying that two companies prior to the acquisition operated independently of and perhaps in competition to each other. This newly formed post-acquisition entity might appear more established - and this to both insiders and outsiders when the legal, technical, economic and physical / geographical boundaries that defined each company prior to the acquisition are redrawn, dismantled, or merged. Correspondingly, investors and other stakeholders to the formation of the 'new' company are likely to perceive and / or calculate the relative 'success' or 'failure' of the acquisition in response to how the newly formed company appears to perform: for example, whether the potential assets and, by extension, sources of synergy that defined each pre-acquisition company are being integrated in a manner that expresses strategic concordance as opposed to strategic disharmony or discordance.

Pucik et. al. (2011) offer in-depth research into M\&A activities among Japanese companies and conclude that stakeholder perceptions / assessments of 'success' appear to be contingent on what expectations each side set for the investment. As an expression of 'strategic intent', the expectations might be communicated in an explicit manner: for example, in the form of a written agreement or contract defining the terms and conditions for integration during the pre-, during and post-acquisition processes and specifying clear timelines and milestones of progress towards synergy. These written statements or reports feed into the interpretations of business analysts and other IB 'experts' - a key source of data used in designing our case study. Alternatively, and perhaps inevitably given the complexity of the acquisition and integration processes, such expectations and expressions of strategic intent might occur implicitly and / or on an ad hoc basis: in other words, the strategic intent of each participant in the acquisition and related integration processes might evolve and, at critical moments, remain under- or even un-stated. This tendency that might at critical moments lead to ambiguity, misinterpretation, misunderstanding, frustration, and consequently disrupt and threaten the success of the strategic integration processes and of the cross-border acquisition as an investment (Marsh, Mercer and Kroll, 2008).

Recognizing such threats to intended or expected international business performance, there is an established body of research suggesting that members of nationally defined societal-cultures tend to express their responses to complexity using different styles of communication. To illustrate, Hall (1976) distinguishes between so-called 'high' and 'low context' communication cultures. In 'high context' cultures people tend to understate their observations and emotions: the meaning relevant towards making sense of a current situation is assumed to be 'in the person' as opposed to 'read' in detail from the person's visible behaviour. In contrast, people in 'low context' cultures tend to prefer information to be made explicit and shared as a common point of reference rather than 'private' to individual interpretation. In Hall's analysis, Japanese people tend to prefer high context styles of communication: each person should understand what needs to be said or left unsaid by their recognition of the social and communication context. In contrast, people in low context cultures such as Germany or North America tend to expect other people to 'speak their mind' in order to reduce ambiguity and / or avoid misunderstanding. Echoing earlier discussion of M\&A 'control', the extent to which a transaction referred to in explicit terms as a 'merger' might be recognised subsequently as an 'acquisition' in terms of the unspoken strategic intent of the acquirer - a factor 9as we shall see) in how managers NSG sought to present themselves as 
equal partners' to managers in a company they had just acquired and strategically (legally/financially) controlled. In contexts for international management education, one vivid illustration of senior management failure clearly to express 'strategic intent' remains the espoused 'merger between equals' and subsequent (and spectacular!) failure of the Daimler-Chrysler 'marriage' (Watkins, 2007). A parallel example among senior Japanese managers is the acquisition of US-based tyre-maker Firestone by Japan's Bridgestone in the late 1990s. Firestone was bankrupt; the Japanese investors had decided to adopt a twenty-year timeline for synergy and thus refrained from making radical changes to the acquired company - perhaps out of a wish to 'demonstrate respect' (Pucik et. al., 2011; Pucik, 2008) and, as we later suggest, as an expression of 'patient capital' that appears distinctive to Japanese investors (Jackson \& Matsumoto, 2016). According to Pucik et. al. (2011), 'talented' managers at Firestone who had welcomed the acquisition as an opportunity to improve the working culture and business performance began to leave the new company 'in droves'. As we illustrate in the case study, senior managers at NSG made strenuous efforts top both identify and retain the 'talent' they acquired with Pilkington and, as a form of reverse integration, radically adapt their own 'talent management' policies and practices during the post-acquisition period - one factor, we suggest, for their ultimate business success.

\section{Methodology}

The ontological position adopted as a premise for this article is that the reality of organisational development can be observed and described using publicly available sources of business data, comparing these observations and descriptions iteratively and critically with coded testimony from semi-structured interviews with key participants during the acquisition and post-acquisition/strategic integration processes.

\subsection{Research Questions}

Against this background of IB practice and research presented thus far, this article is designed to address to two main research questions:

RQ\#1: What discernible patterns of strategic integration appear relevant towards explaining both the initial 'failure' and the subsequent 'success' in achieving synergy at NSG-Pilkington?

RQ\#2: To what extent might the discernible patterns of strategic integration towards achieving synergy in the case of NSG-Pilkington be identified as distinctly Japanese in origin and type?

As will become clear in the 'Discussion' section of this article, one test of validity for answers we can draw from the NSG-Pilkington case study in response to these two questions will be the extent to which they appear generalisable to broader contexts for IB practice and research.

\subsection{Methods}

In addition to the review of IB literature presented above, the case of NSG-Pilkington forming the core of this article has been generated using sources such as firm reports and business analyses (in English and in Japanese), on-going interviews and conversations with senior managers at NSG, Pilkington and the (now) NSG-Pilkington Group along with evidence we have gleaned in our professional lives working with managers and business analysts in Japan and in the UK, including senior managers at both NSG and Pilkington.

\subsection{Case Study}

The primary method chosen to address the two research questions listed above is a company-specific case study. In contexts for business research, Saunders, Lewis and Thornhill (2012) define a 'case study' as 'a research strategy that involves the empirical investigation of a particular contemporary phenomenon within its real-life context, using multiple sources or evidence'. Interestingly, Richard Yin - a prominent expert in using case studies for research -refers to the case study as a 'method', chosen in order to identify and collate from multiple sources of data (Yin, 2014). According to Yin (2004), using case study research designs is distinctive in that the researcher is commonly challenged to analyse or, at least, organise data as they are gathered. In response to this challenge the onus is on researchers to control repeatedly for research and data bias: for example, in the design of the questions being asked and the observations selected for analysis - a caution holds true for any design and engagement in 'real world' research (Robson, 2002). By de veloping the case study longitudinally over a period of eleven years, we have been able to examine long term post acquisition performance rather than focusing on immediate impact of deal announcement in share price, since expected synergy is assessed to have been achieved as a strategic objective by years of effort by senior managers (initially) in the acquiring company and - through time - by managers across in the newly formed company. Adopting a longitudinal approach has also allowed us to 'repair' and clarify distortions caused by (inevitable) researcher and respondent biases. 


\subsection{Semi-structured Interviews}

Semi-structured interviews were conducted successively with senior managers at NSG and Pilkington in the UK and in Japan - and in English and in Japanese - during the period 2014 to 2016. Coding for the interviews was adopted from various models of strategic integration, and primarily from Beer, Eiesenstat and Spector (1990). The four-phase approach conceptualised in this model was adapted to include emphases to the identification and retention of 'talent' (Jackson, 2011). This was in order to accommodate the espoused strategic intent among senior managers at NSG to target the adoption of Pilkington's 'talent management' policies as a benefit leading to synergy during the strategic integration process.

\subsection{Research Reliability and Validity}

In combination with the other sources of data used to develop the case study, Correspondingly, we claim to have achieved 'real world' insights into how post-acquisition investments in investment towards achieving synergy at NSG-Pilkington acquisition have evolved through boundaries periods of time and international business 'space' (Yin, 2004; Kurihara, 2006). While accepting the inevitable threats to the validity and reliability of data generated through case study research in terms (for example) of selective and cognitive bias on the part of researchers and participants, the choice of case study as a primary research method in respect of NSG-Pilkington benefits from a systematic, multi-perspective, triangulated and critical interaction within spaces and across time periods defined dynamically and longitudinally, thereby corresponding to the 'real world' experiences of IB practitioners in a publicly listed company.

\subsection{Research Ethics}

The quantitative data used to develop the case study are publicly available; as illustrate din the Figures and Tables informing the case study, interpretations of these data by business analysts have been adopted and amalgamated without distortion. The qualitative data generated by the semi-structured interviews were summarised, coded and shared with the respondents for comment before being used in this article. The comments of senor managers at NSG, Pilkington and NSG-Pilkington were anonymised before being aggregated. The role adopted by the co-authors of this article were defined explicitly and according to time, place and purpose as 'visitor' (observer), 'researcher', and (when requested by respondents) as 'consultant'.

\section{Case Study}

In May 2016 Nippon Sheet Glass (NSG), one of the world largest suppliers of industrial flat glass, announced that they ended its fiscal year (FY) 2015-16 with net loss of JPY 49.5 billion (USD 495 million) (NSG, 2016). In contrast, the financial situation in the months leading to the commencement of FY 2017-18 suggests a much more positive picture, with dividends prepared to be paid out to investors and global sales and market share to increase dramatically (Nikkei, 2017; Financial Times, 2017). This case study illustrates how this business turnaround has been achieved.

\subsection{Business Performance}

The loss reported at the end of FY 2015 was the sixth time that NSG disappointed its shareholders by reporting net loss since NSG purchased Pilkington in 2006 (See Figure 1). Although NSG`s management explained that slowdowns in the economies of emerging markets such as China, Vietnam, Russia and Brazil caused the downturn of business performance, one of NSG's main rivals, Asahi Glass, reported net profits of JPY42.9 billion (USD 429 million) while Central Glass reported a net profit of JPY 10.1 billion (USD 101 million) in 2015. NSG's continuing poor performance could not therefore be explained solely by reference to external economic strategic environments define the industrial glass production sector. In fact, one of the reasons NSG decided to acquire Pilkington was to overtake its competitor, Asahi Glass - currently the world's largest sheet glass supplier, especially to automotive manufacturers. Asahi Glass grew its overseas business by acquisitions: for example, becoming a 100 per cent shareholder of Belgium's Glaverbel S.A. in 2002 - a move that gave Asahi Glass control over plants in Belgium, The Netherlands, Czech Republic, France and Italy. The revenue was Euro 1.7billion at the transaction. Whereas NSG has continued to struggle to improve performance even 10 years after the Pilkington acquisition, Asahi Glass has achieved consistent profit growth, even during the global financial crisis since its acquisition of Glaverbel (See Figure1). NSG's relatively poor business performance appears to lie inside the firm; notably, the failure to generate synergy from Pilkington acquisition. 


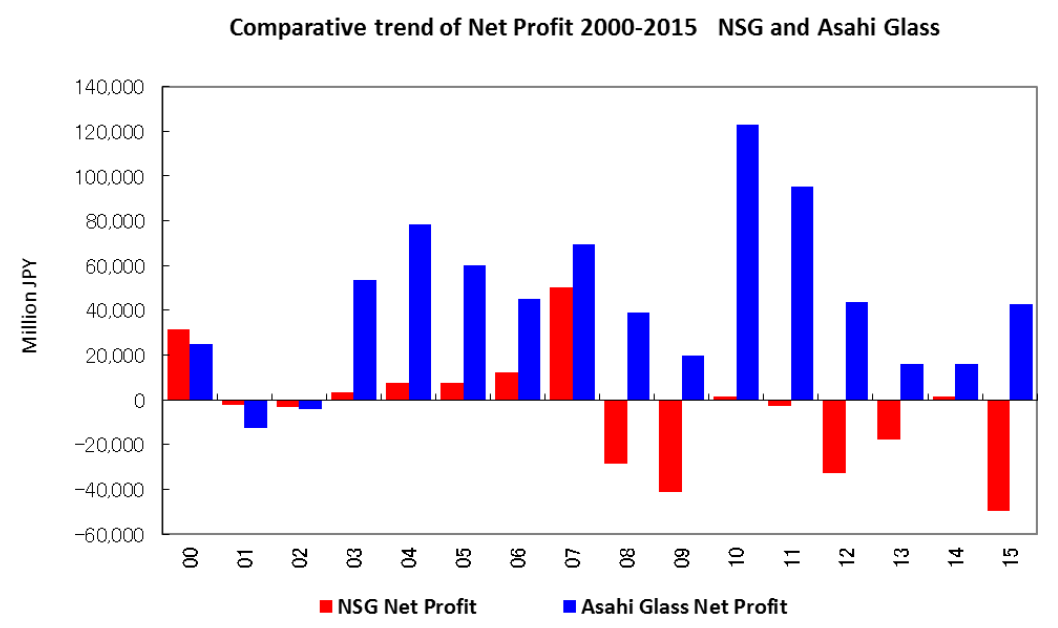

Figure 1. Comparative trend of net profit 2000-2015 NSG and Asahi Glass (Source NSG and Asahi Glass Securities Reports)

\subsection{Strategy}

The JPY 616 billion (USD 6.16 billion) acquisition of Pilkington by NSG was seen as a touchstone for a Japanese firm's entry into the global market; notably, because Pilkington's sales volume at that time was more than double that of NSG. Thus, the acquisition can thus be seen as a case of 'the smaller swallowing the bigger'. NSG had already made a ten per cent capital investment in Pilkington in 2000, before raising its share to twenty per cent in 2001. NSG and Pilkington were in an affiliate relationship by the time of the acquisition in 2006, which suggests that NSG had some degree of understanding of Pilkington's core operation and their actual and potential strategic value.

According to Japanese press release of February 27, 2006 (NSG, 2006), senior mangers at NSG cited the following as key strategic motives for the acquisition: - To achieve the largest share in the global market of industrial sheet glass - To become a global player with economies-of-scale and technological fusion - To accelerate the realization of the firm's stated vision 'to be a firm with a global presence' - To make the most of the synergy effect in product development and technology in which Nippon Sheet Glass and Pilkington had accumulated expertise.

According to a financial result report for fiscal 2006, the combined NSG and Pilkington annual sales volume increased from JPY 265billion (USD 2.65 billion) in 2005 to JPY 681 billion( USD 6.81 billion) in 2006, thereby becoming equal to Asahi Glass in scale. NSG`s sales outside Japan increased from 17 per cent to 67 per cent, of which European markets accounted for 43 per cent of the total sales after the transaction (see Figures 2 and 3 ). On a combined basis, NSG owned 46 float lines, manufactured in 26 countries, produced 6.4 million tonnes annual output and maintained sales offices in more than 130 countries. The workforce increased to 36,000 worldwide from 12,000 before the acquisition, and the number of global subsidiaries also increased from 52 to 237 . It is apparent that strategic considerations of incremental capacity and increased market share in flat glass business were paramount. In sum, extending the scale of NSG business presence was a key element towards justifying the Pilkington transaction.

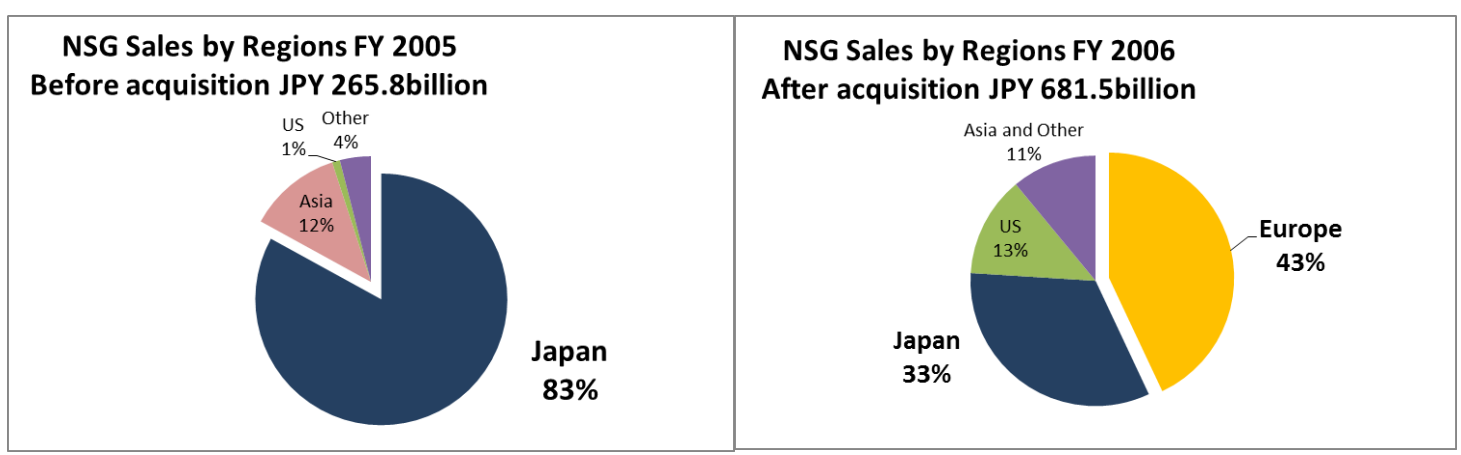

Figure 2 and 3. NSG Sales by region FY 2005 and FY 2006(Source NSG securities report segment information) 
Overall, NSG management was confident about post-transaction management, because there was little geographical overlap between two firms. NSG operates mainly in Japan and Pilkington has significant presence in Europe, North America and South America. In addition, NSG and Pilkington have maintained relations in the form of a technical alliance for twenty years. NSG had minority shareholdings in Pilkington since 2000. NSG believed both could run the global operation well together. As a result of the acquisition, NSG/Pilkington supplies every major automotive OEM around the world. According to the NSG`s presentation at the acquisition in 2006, they introduced their strategic rationale for NSG as follows: - Substantially to enhance geographic spread to mitigate industry cycle and generate stable earnings and cash flow.- To increase presence in emerging markets such as China, South East Asia, South America and Russia.- To distribute NSG`s value-added products outside Japan through Pilkington`s network and access to Pilkington`s European manufacturing process technology. With this complementation, NSG managers predicted to create the synergy amount of JPY10 billion (USD 100 million) in 2012 and JPY19billion (USD 190 million) in 2014. The synergy was expected to come from cost improvement by global procurement program, cross selling, and joint production investments. As a result, NSG came to acquire the second largest share in the global market of sheet glass for vehicles and construction, following Asahi Glass. Before the acquisition, more than 80 per cent of the company's sales came from the domestic market. However, after the acquisition, 40 per cent came from the European market and 30 per cent from the domestic market. This acquisition was also meant to benefit from 'buying time' in order to become a global firm by acquiring a share in a global market.

\subsection{Integration}

In April 2007 NSG announced a new organizational structure designed to integrate Pilkington operations. NSG explained that the objective of the first phase of the integration strategy was to achieve the establishment of an integrated Flat Glass Business, which occupies almost 90 per cent of sales and profit of the operation. NSG established a new global Flat Glass Business, which included all the activities formerly in NSG and Pilkington, the development, manufacture and sales of NSG flat glass products worldwide. A headline aspect of the restructuring saw Stuart Chambers from Pilkington becoming the Chief Executive Officer of the new global Flat Glass Business product line (see Figures 4 and 5).

The Flat Glass Business consists of a Global Building Products Business Line, which led by Stuart Chambers and a Global Automotive Business Line, led by Pat Zito, who also came from Pilkington. At the same time, a Global Headquarters (GHQ) was established by reorganizing the existing corporate staff and is to work as a head office and support function for the combined group. As we illustrate when presenting (below) testimony from interviews with NSG and Pilkington managers, the post-acquisition restructuring of NSG invited Pilkington managers to head key operations. In short, NSG and Pilkington managers started to implement a co-operative strategy towards creating synergy, as had been promised to key stakeholders (See Figures 4 and 5).

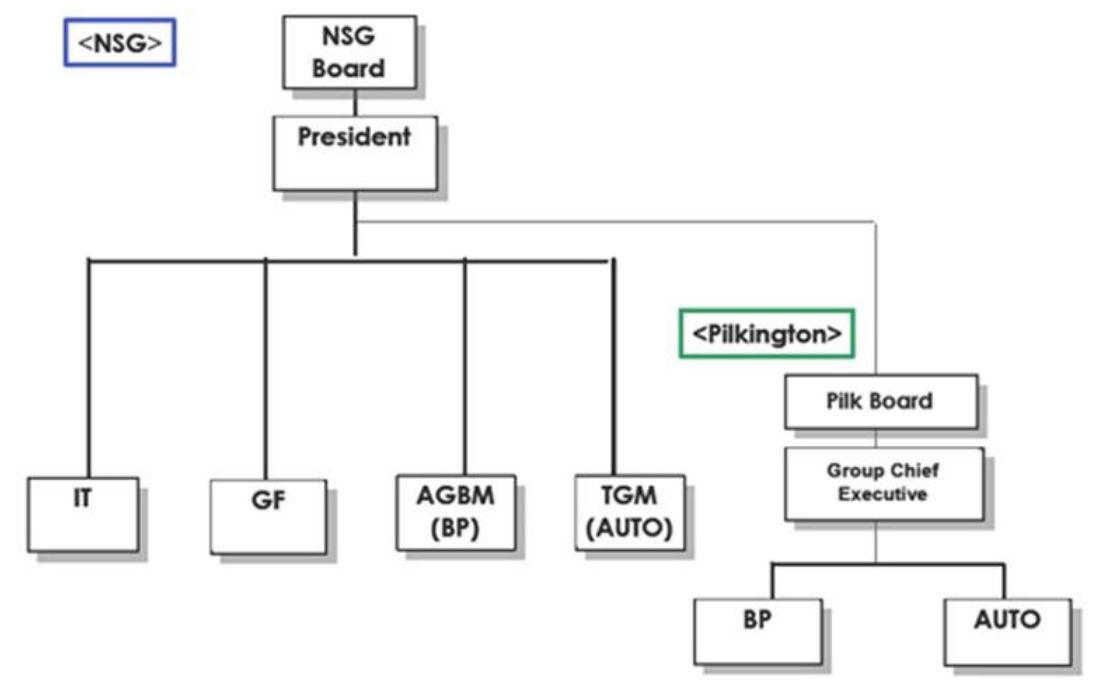

Figure 4. Organization Structure right after the transaction in 2006 (Source: NSG Press release, January 15, 2007) 


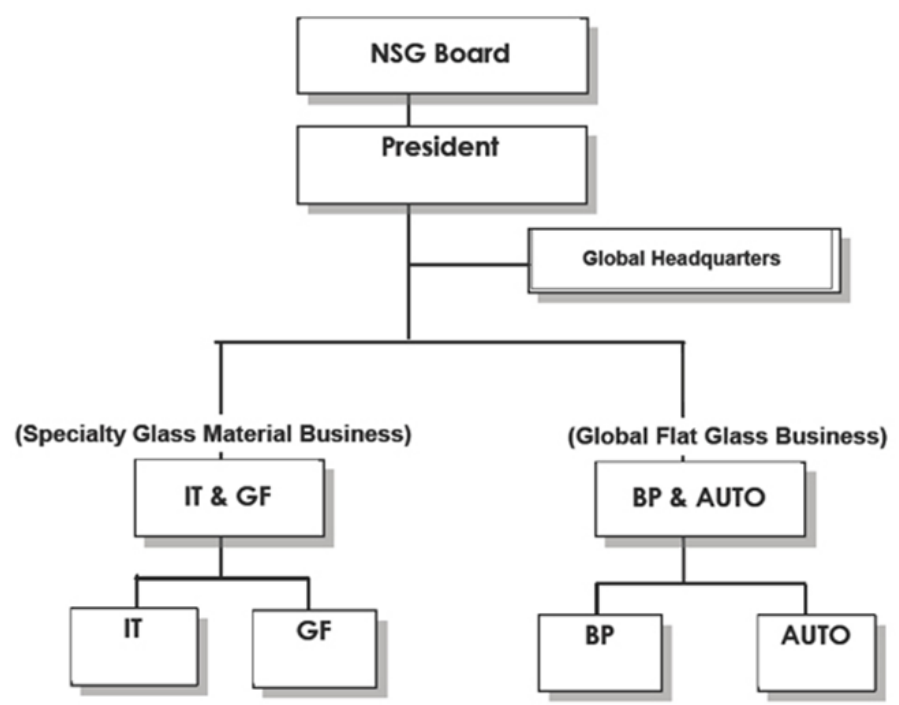

Figure 5. New organization in 2007 and following appointments (Source: NSG Press release, January 15, 2007)

Note. Pilkington management became a head combined Building Products and Automotive Flat Glass business in 2007. Stuart Chambers, former CEO of Pilkington became President of NSG in 2008. Pilkington management occupied half of the NSG board seats in 2008.

\subsection{Synergy}

Running the business turned out to be difficult after the acquisition. NSG reported an increase in income and profit in 2007, immediately after the acquisition; howe ver, for the following two years NSG reported losses. From 2011 NSG reported a net loss for three years in a row, as production facilities and employees inherited from Pilkington became burdensome owing to the then European debt crisis. Total sales amounts of NSG decreased to JPY629billion (USD 6.29 billion) in 2015 from JPY 866 billion (USD 8.66 billion) at the peak in 2007 (see Figure $6)$.

NSG Trends of Sales 2004-2015

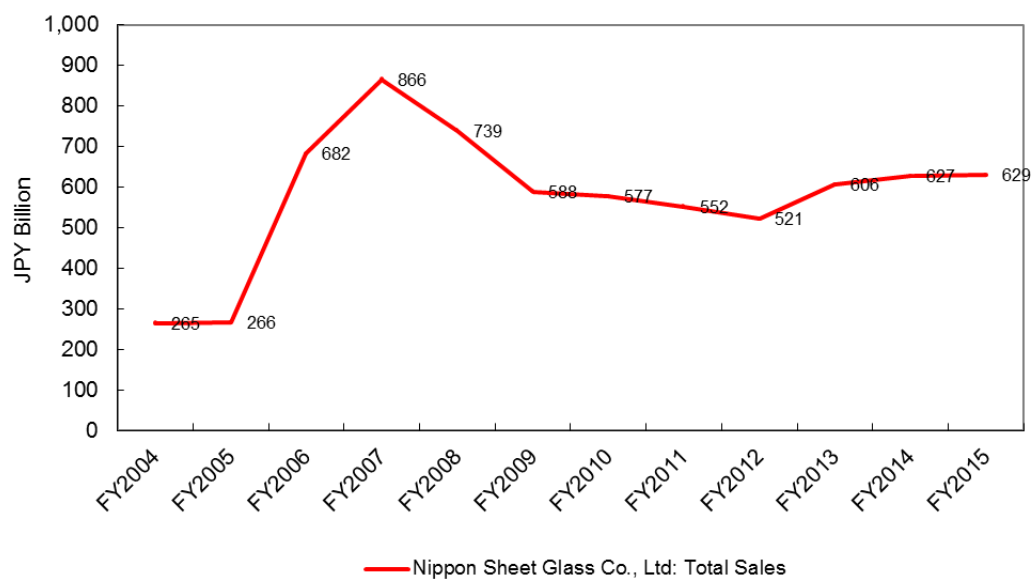

Figure 6. NSG Trend of Sales 2004-2015 (Source NSG Securities Reports)

As stated previously, after the acquisition, about 40 per cent of total sheet glass sales for vehicles and construction came from the European market. However, owning a large share of a regional market makes a firm susceptible to changes in the region's business environment. Production facilities and employees obtained through the acquisition quickly became excess capacity, owing to the economic slowdown brought about by the European debt crisis. When European sales halved, NSG had to manage their resources by restructuring Pilkington. In all, 5,800 jobs were cut in 2009 , followed by a further 3,500 in 2012. The expected multiplier effect and the reduction in costs failed to materialize. In addition, when a firm needs to restructure a purchased firm, the benefit of buying time disappears. Due to the insufficient operating cash flows, NSG has been constrained to make proper investment activities but had to focus on its restructuring during the last 10 years. NSG acquired the scale and 
global presence they wished but that actually caused a decade consecutive poor performance (see figure 7).

NSG Trend of Cash Flows 2004-2015

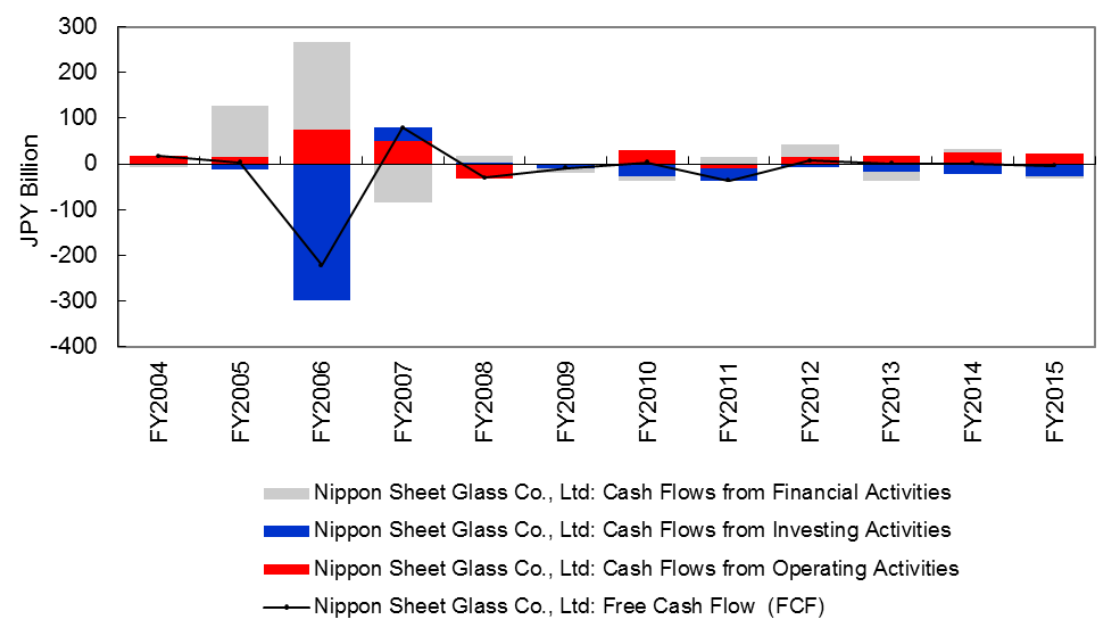

Figure7. NSG trend of cash flows (Source NSG Securities Reports)

In terms of the strategic integration effort, NSG tried hard to make the most of Pilkington's human resources. In 2008, two years after the acquisition, Stewart Chambers, the president of Pilkington, was appointed president-cum-CEO of Nippon Sheet Glass HQ, and tasked with transforming the firm into 'a world number one glass manufacturer' in business size and financial performance. At the time, four of the eight executive directors (excluding outside executive directors) of NSG were from Pilkington. Katsuji Fujimoto, the then President of Nippon Sheet Glass, explained that 'Nippon Sheet Glass is no longer the Japan-focused NSG of the past. It is natural to have western CEO to lead global organization' (Nikkei, 2008) However, the impact of these senior appointments did not turn out as hoped or expected. Upon assuming the position of NSG-Pilkington President Stewart Chambers replaced half the executive officers of NSG with non-Japanese appointments, and decided to reduce the firm's production capacity and number of employees. However, he then left the position within a year - reportedly for family reasons. Chambers had joined Pilkington in 1996, and served as group chief executive from 2002 to 2006. He had an impeccable business record; howe ver, he appears not to have had much loyalty to NSG, the new owner. After Chambers, a Vice President of DuPont, an American chemical firm, was appointed as a new and second non-Japanese president. However, the new president only lasted two years.

The acquisition of Pilkington also appeared directly to damage NSG`s balance sheet. The transaction brought the firm into a highly leveraged financial position. NSG`s interest bearing debt remains around JPY 400billion (USD 400 million) and the firm had to ask its partner banks for the additional commitment line of JPY 25 billion (USD 250 million) in 2013 due to the continuing poor performance of Pilkington business. NSG`s debt/equity ratio became 4.15 times; for comparison, the Asahi Glass debt/equity ratio was only 0.43 times. NSG paid JPY 18billion USD 180 million) for interest and other debt related expense in 2015. NSG`s recent credit rating became assessed at BB+; Asahi Glass was rated A-. The NSG operation continues to be highly leveraged, which is unusual among major manufacturing firms in Japan (see Figure 8). 


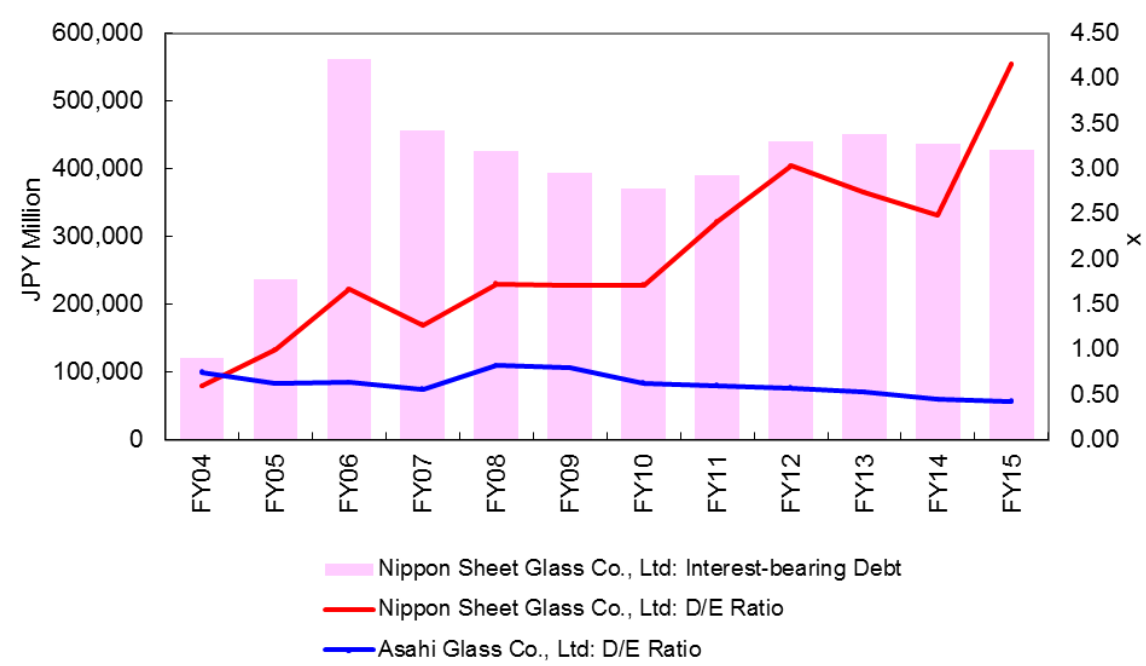

Figure 8. NSG trends of leverage 2004-2015(Source NSG securities Reports and Asahi Glass securities Reports)

\subsection{Talent Management}

The above description in relation to NSG-Pilkington's emerging strategy gives context to a number of human resource management (HRM) issues underpinning the relative ups and downs of the company post-acquisition business performance: specifically, in relation to achieving synergy. The testimony extracts summarised here came from semi-structured interviews with senior managers at NSG-Pilkington in addition to observations and informal conversation with managers and other key stakeholders in the strategic integration progress. The testimony is organised in 'phases'. This echoes the model proposed by Beer et. al. (1990), an established approach guiding investments in strategic integration with emphasis on HRM decisions. The emphasis on 'talent management' derives from the pilot interviews conducted with managers in order to establish a coding frame for the interview data. Verbatim comments appear between "inverted commas".

Phase 1: Re-assigning roles and responsibilities relevant towards achieving synergy

Senior managers at NSG identified themselves as expert in its domestic market and lacking of global business experience, one of the key motivations to invest in the acquisition of Pilkington, which - in their view and experience - had established a stronger global market presence than NSG had achieved. To illustrate, over the post-acquisition period, NSG moved from a market (global sales) balance of 80 per cent domestic and 20 per cent overseas before the acquisition to a balance of 20 per cent domestic and 80 per cent overseas after the acquisition. Given that this transformation formed a core objective of NSG's FDI strategy, senior managers decided at an early stage in the integration process to invite senior executives from Pilkington to the Board level at NSG headquarters in Tokyo. According to NSG managers, the ownership structure of the Japanese company allowed that these Executive Board appointments were "genuine" and "strategically influential" in the sense that they were not merely "cosmetic": in other words, NSG avoided "changing a few faces at the top" in order to give the Japanese company the appearance of "becoming more global" while resolutely remaining Japanese in its strategic orientation and behaviour.

Phase 2: Coaching and training in skills and competencies relevant towards achieving synergy

Senior NSG managers used the influx of "new faces" and "executive voices" at the Board level in order to signal that the company was becoming "more global". The demands of synergy meant that existing NSG managers needed more than "crash-courses in business English skills". Rather than investing in training for such important yet relatively narrow skill-sets, managers in the Japanese company who appeared ready to "buy into" the acquisition were invited to apply for "global leadership development programmes", where training for skills were balanced with developing competencies that should not only add synergy to the newly formed company. Under the slogan 'Every employee can be a future CEO' there was a systematic effort to "sort out the talented from the less talented" and "the committed from the less committed". Within three years, 30 per cent of senior managers at NSG had quit of been "encouraged to retire". 
Phase 3: Re-aligning recruitment, succession planning and rewards policies and practices relevant towards achieving synergy

The targeted "shedding" of (mostly) older employees who appeared reluctant to develop a "global mind-set" signalled a shift in policy that challenged the traditional status of seniority in Japanese employment, whereby length of service (loyalty) might guarantee lifetime employment by one company. According to senior managers at NSG, one "excuse" commonly used to justify the sudden introduction of such (in common Japanese perception) "radical" succession planning and rewards policies and practices was to announce these as "global" human resource and talent management policies and practices that had been "inherited" from Pilkington. Being more than twice the size in terms of employee numbers than the Japanese acquirer, NSG managers argued "it would be too complex and too expensive" to attempt a transfer of Japanese-style recruitment, succession planning and rewards policies and practices in the opposite direction.

Phase 4: Fine-tuning and formalizing new management and leadership systems relevant towards achieving synergy

Fortunately for NSG, the competence of the senior managers and executives transferred from the UK to Japan proved to be of such quality that both internal and external stakeholders to the new company accepted as "normal" having "foreigners" in senior decision-making positions. One feature of this transformation is the observation that immediately after "the first wave of British managers" was transferred from the UK to Tokyo, NSG began recruiting a new generation of non-Japanese managers or of Japanese managers who had received business and management education overseas. To illustrate, by June 2016 - ten years after the acquisition of Pilkington - the Board of Directors of the newly formed company comprised five Japanese, one Austrian, and one German. In the assessment of NSG-Pilkington managers, this shift in company profile illustrates how the initial and then supplementary objectives of the strategic integration process appear to have been achieved and, consequently, current business success secured.

\section{Discussion}

Having now presented a selection of case study data, we can re-invoke the first of our research questions:

What discernible patterns of strategic integration appear relevant towards explaining both the initial 'failure' and the subsequent 'success' in achieving synergy at NSG-Pilkington?

First of all we should note that the current assessment of business 'success' at NSG-Pilkington is tentative: however, in respect of restored financial health, the success is real. Correspondingly, the case study illustrate how quality of product linked to market demand and the availability of global distribution networks are key factors influencing the competitive performance of manufacturing companies regardless of business sector. NSG was big and bold enough to acquire a larger if familiar and (it appears) accommodating business rival. In strategic terms NSG's acquisition of Pilkington can be categorized as a 'roll up' type in which the acquirer seeks to consolidate business in a maturing industry, thereby seeking benefit through horizontal integration with the objective of reducing operations and transaction costs. The acquirer integrates business they bought into an existing model, and then sheds what are assessed to be redundant resources. By using the target`s resources, the scale economics drives down operating fix costs and that (in theory) boost business performance.

However, the synergy model NSG adopted was one whereby they kept Pilkington`s operation as a whole and increase its production scale as worldwide without consolidation. The primary objective of NSG management was "to be a firm with a global presence;" rather than creating financial profits by consolidating target operation at least in the short-term. As illustrated in the appointment of Pilkington executive to senior positions in Japan, NSG managers perceived complementarity opportunities by granting high levels of authority to resources already available in the acquired company. Ho wever, this approach served initially to reduce rather than enhance the value leveraging opportunities that these complementarities or similarities in company profiles might have allowed (Zaheer, et. al., 2011). Secondly, and at an initial glance, the re-structuring that ensued within the newly formed NSG-Pilkington appears "radical", as claimed by one of the Japanese managers interviewed. In fact, NSG did not start shutting down and reducing workforce numbers until they faced financial problems in 2009. The flat glass business is cyclical; NSG completed the acquisition at the downturn of the cycle in 2006. NSG did reduce the scale of the acquired Pilkington operation: for example, the number of major float lines fell from 34 to 26 . However, this leveraging process took around ten years. By international comparison this action was slow and furthermore appears a re-active move in response to poor performance rather than a pro-active decision to achieve synergy. More specifically, NSG maintains 199 subsidiaries compared to 53 before the acquisition. They have reduced total workforce by 24 per cent since 2006, but the sales declined by 28 per cent during the same period of time (See Figure 9). This implies that the restructuring that NSG implemented has been failing to keep up with changes in the 
external business environment, adjusting to fluctuating market demands rather than pursuing synergy. Instead, the re-structuring efforts appear to have threatened both return on assets (ROA) and return on equity (ROE) performance over recent years (see Figure 10). NSG`s economies-of-scale approach to strategic integration appears better positioned now they have acquired Pilkington's global networks. However, they have struggled to reduce operating fix costs. NSG`s 10 years post transaction performance shows that for horizontal integration type of transaction, especially in matured cyclical sector, the delay of consolidation work, in other words, retaining higher fixed cost could damage the acquirer's business in the long-term.

NSG headcounts 2004-2015

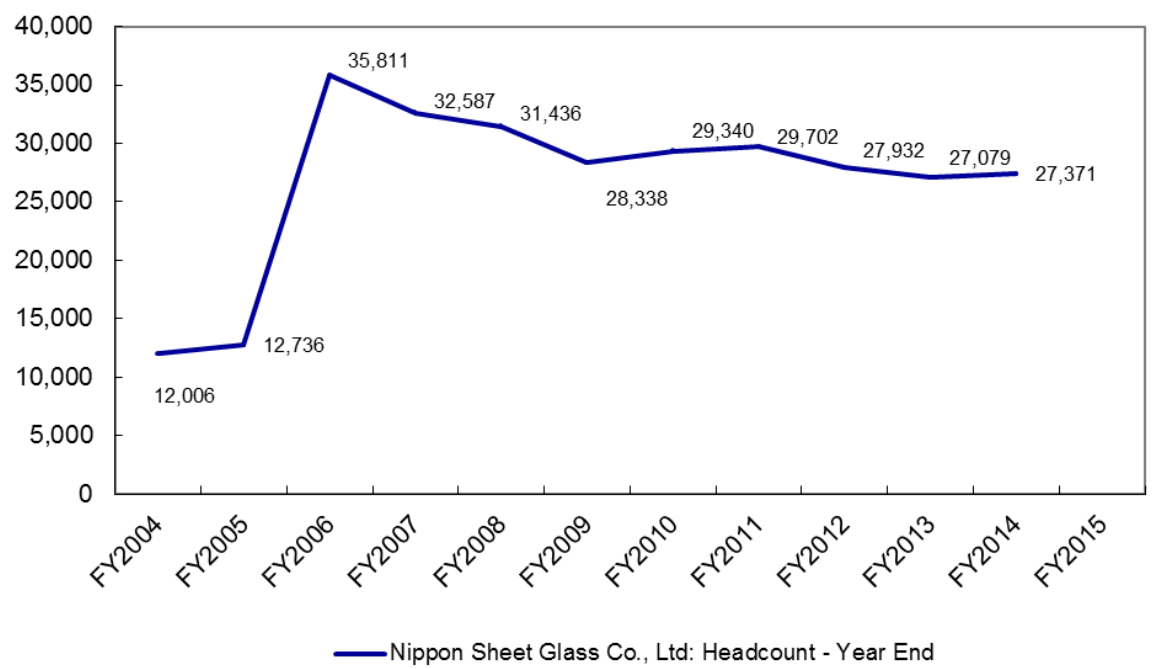

Figure 9. NSG headcounts 2004-2015 (Source NSG Securities Reports)

NSG Historical ROE/ROA

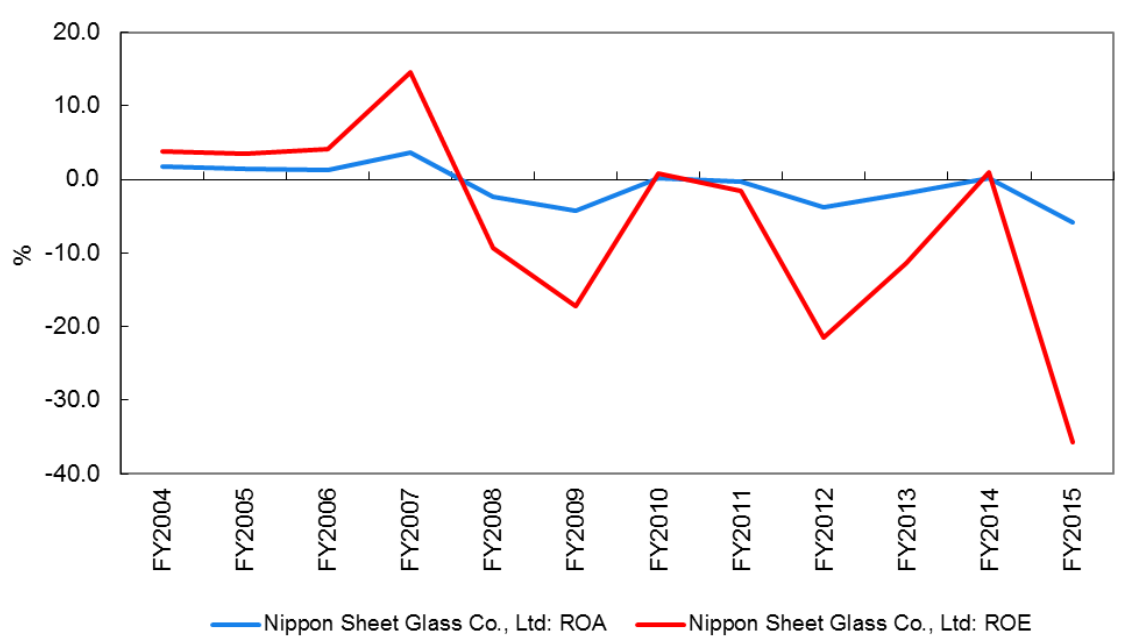

Figure 10. NSG ROE and ROA (Source NSG Securities Reports)

It is in recognition of this reality and threat that emphasises the strategic value of having 'patient' investors. NSG entered the acquisition process with the backing of established business networks: for example, a long-standing and mutually respecting relationship with global customers such as Toyota - a form of strategic mind-set we referred to earlier as 'keiretsu'. Consequently, when at the transaction stage NSG claimed to be 'buying time' by acquiring Pilkington they were able to take a longer term view on integrating human, knowledge and other key strategic resources from Pilkington. Given the fact that Pilkington was so much bigger in size and international reach than NSG, the opportunity to transfer senior executives from the UK to Japan appears not only attractive and (in retrospect) almost inevitable. NSG did buy time to increase production capacities around the world by the acquisition and became a world number two player in terms of sales. However, one key objective of acquisition 
investments is to deliver greater and sustainable profit growth by creating synergy shortly after the transaction, since the acquisition process itself sucks in considerable financial resources, including premium payments. It is under such conditions that the availability of 'patient capital appears to offer a key strategic advantage (Boyer, 2014; Jackson, 2016).

With hindsight, an alternative strategy towards achieving post-deal synergy would be to embark with a step-by-step approach. Here, the real meaning of 'buying time' involves identifying possibilities to accelerate profit growth through acquisition rather than merely adding assets and market share. These latter performance measures can count as 'success' for as long as the acquirer can pay what the target demands. However, such measures alone form no basis for sustainable profit growth, which depends on whether the acquirer can actually achieve synergy. Having said this, adding 'global' assets can appear attractive to a domestically-oriented company seeking to follow major customers into overseas markets: though inexperience - or venturous excitement managers might become confused when a major competitor becomes available for sale and key investors and other stakeholders give a 'green light' to the proposed deal (Jackson \& Matsumoto, 2016; Matsumoto, 2014).

Correspondingly, a fourth discussion point concerns the radical transformation of NSG's established approaches to HRM - notably, to the identification, retention and promotion of 'talent' (Jackson, 2011). It is common for overseas acquirers to rely on local managers with local knowledge - at least, in the initial stages of post-acquisition control. However, as illustrated by the aforementioned Daimler-Chrysler and Firestone-Bridgestone examples, developing a timely and consistent approach to talent management is a determining factor in its long-term effectiveness. NSG invited Stuart Chambers from Pilkington to become president of NSG headquarters in Japan; however, he resigned only one year later - in traditional contexts for Japanese business, a headline-making appointment followed by an apparently spectacular failure.

However, and as evinced in the interview testimony, senior managers at NSG were looking for an opportunity (or excuse?) to reform and (perhaps) 'rejuvenate' their HRM polices and practices, aligning them with what might be considered 'global' standards. The evidence suggests that the legacy of Stewart Chambers was positive: NSG managers to this day affirm, "Ste wart-san led by example". Nonetheless, NSG decided to replace the CEO position with a 'home-grown' Japanese appointee in 2012, but a recovery in business performance remained absent. Lessons were learned. Mr Yoshikawa, who succeeded as CEO in 2012, claimed publicly that 'NSG simply did not have capability to control the larger operations like Pilkington and that caused all the poor performance in the past' (Nikkei, 2012).

\subsection{Success or Failure?}

According to recent M\&A research specific to Japanese companies, when acquirers do not have scale advantage at the acquisition ('deal') stage, either in sales or production capacity against target, the investment is more likely to result in failure than in success (Hemmert \& Jackson, 2016; Jackson \& Matsumoto, 2016; Matsumoto, 2014; Pucik et. al., 2011). To illustrate, between 1985 and 2012 a total of 51 out of 116 Japanese outbound transactions worth US $\$ 100$ million and above resulted with the acquirer exiting the purchased business with a loss. Among these 51 failed transactions, more than 60 per cent did not have scale advantage at the transaction or initial deal stage (Matsumoto, 2014).Against this background, NSG's 'failure' to achieve synergy through the acquisition of Pilkington appears, in retrospect, inevitable. Senior NSG management appears to have bought into all the expected benefits of acquisition without paying sufficient attention to the downside of rapidly adding scale. They kept the complementation approach and allowed a higher fixed cost operation; their systematic attempts at horizontal integration in what was a highly matured global business sector required more consolidation in order to generate any real or lasting synergy. Overall, NSG appeared incapable of managing larger scale operation on an international scale and therefore had to rely on managing to specific and pre-ordained targets - as it turned out, without much success. Failure to think and act strategically beyond such targets delayed the restructuring of both the target and the parent businesses and caused consecutive losses from 2006 to 2016.

The extended 'failure' of the NSG-Pilkington acquisition served to strain the traditional 'patient capital' relations that Japanese firms commonly enjoy with their investors (Matsumoto, 2014). Investor demand for 'success' never receded between 2006 and 2016, perhaps prompting senior NSG-Pilkington managers to 'up their game in relation to strategic integration and synergy creation, thereby offering investors and other key stakeholder groups a more realistic prospect of a return on the risk of NSG's (in pure financial terms) unprecedented crossborder acquisition of Pilkington.

Consequently, and tilting the scales of performance ever more towards an assessment of 'success', NSG-Pilkington appears now in a stronger position to leverage its recently acquired global reach, not least through 
a systematic process of 'globalising' its management thinking and strategic decision-making - a turnaround from which their long-time 'patient' investors appear set to benefit from.

\section{Implications}

Once formalised and made explicit or 'espoused' by senior managers, a 'strategy' can be visualised as a distinct social-cultural construct specific to national, regional, sectoral and organisational culture (Morgan, 1989); by extension, the formalisation and perhaps naming of a particular 'strategy' can appear as a factor determining distinctive and (from a business stakeholder perspective) patterns of strategic leadership thinking and behaviour (Schein, 1992). As such, the implementation of a strategy can be conceptualised as the expression of normative expectations that managers of particular backgrounds and ambitions will bring to any strategic investment decision, and especially under the pressure generated by a large-scale cross-border acquisition.

In the case of managers at NSG, and in relation to what we have discussed here linking strategic integration to the pursuit of synergy, we can speculate that such normative expectations coupled to the recognition of needing to satisfy key stakeholders such as NSG investors. As Pucik et. al (2011) suggest, what might be explicitly and 'officially' heralded to both external and internal stakeholder groups as a 'merger' might, in terms of financial, technological, human and other forms of strategic resource control in fact be an 'acquisition' in everything but name, and especially - as we discuss subsequently - in cases where the 'name' given to the investment derives from the Japanese (Matsumoto, 2014). One implication here for future IB researchers and practitioners is to seek clear assessments - consistently and iteratively over time - not only of a company's espoused strategy, but also of senior management's strategic intent. In contexts for IB research, this insight reflects key elements in the approach adopted in this article: for example, developing a longitudinal study, combining both emic and etic perspectives though the engagement of a joint 'insider-outsider' research team, with the foundations for research triangulated against academic, professional and practitioner inputs.

In terms of the topics that IB researchers might choose to focus on, the case study presented in this article contributes to an established body of academic and business consultancy research suggesting that 'people factors' remain key towards ensuring the success of the strategic integration process, towards reinforcing the identification and generation of synergies, and thus of securing the success of the acquisition investment overall. To illustrate, Kay and Shelton (2000) identify key factors for 'success' and (in their relative absence) 'failure' before, during and after the formal acquisition event. These factors include: effective communication; retention of influential executive level managers; retention of key talent at all management levels; effective cultural integration. Pucik et. al. (2011) offer a practical reminder that whatever is defined as the 'strategic integration' phase of the acquisition investment starts in the minds of key participants before any practical investment is made in seeking to identify and integrate assets in pursuit of synergies - a process of identification that should begin during the aforementioned due diligence phase prior to acquisition (Evans et. al., 2010).

Highlighting these two implications serve to address the second research questions that motivated this case study. For example, the aforementioned institutional anchoring or (from a research perspective) 'embeddedness' of FDI sourced in Japan might account for some of the over-optimism and under-preparedness of senior managers at NSG. However, they also account for the availability of 'patient' capital. In respect of the radical overhaul of HRM policies and practices post-acquisition, the case study encourages IB researchers and practitioners to look beyond national cultural stereotypes and engage with the commonly 'fuzzy' realities of strategic decision-making of managers whose companies face the simultaneously tempting and threatening opportunities generated by cross-border M\&A activities.

With this article and the case study around which it is formed, we hope to have made some modest contribution towards promoting IB research in the field of cross-border M\&As generally and of Japan-sourced FDI especially.

\section{References}

Bamford, J., Ernst, D., \& Fubini, D. G. (2004). Launching a world-class joint venture. Harvard Business Review, 82(2), 90-100. Retrieved from https://hbr.org/2004/02/launching-a-world-class-joint-venture

Bartlett, C. A., \& Ghoshal, S. (1991). Managing across borders: The transnational solution. Boston, MA: Harvard Business School Press.

Bartlett, C., \& Beamish, P. (2014). Transnational management: Text, cases \& readings in cross-border Management. New York, NY: McGraw-Hill.

Boyer, R. (2014). Foreword: From 'Japanophilia' to indifference? Three decades of research on contemporary, Japan. In S. Lechevalier, \& J. A. A. Stockwin (Eds.), The great transformation of Japanese capitalism (pp. xiii-xxv). Routledge. 
Burgelman, R. A., \& Doz, Y. L. (2001, April). The power of strategic integration. MIT Sloan Management Review, 42(3), 28-38.

Burgelman, R. A., \& Valikangas, L. (2005). Managing internal coporate venturing cycles. MIT Sloan Management Review, 46(4), 26-34.

Capron, L. (1999). The long-term performance of horizontal acquisitions. Strategic Management Journal, 20, 987-1018. https://doi.org/10.1002/(SICI)1097-0266(199911)20:11<987::AID-SMJ61>3.0.CO;2-B

Cartwright, S., \& Schoenberg, R. (2006). Thirty years of mergers and acquisitions research: Recent advances and future opportunities. British Journal of Management 17(S1-S5). https://doi.org/10.1111/j.1467-8551.2006.00475.x

Casson, M. (1982). The entrepreneur: An economic theory. New Jersey: Barnes \& Noble Books.

Caves, R. E. (1996). Multinational enterprise and economic analysis. Cambridge, England: Cambridge University Press.

Caves, R. W., Chirstensen, L. R., \& Diewert, W. E. (1982, March). Multilateral comparisons of output, input, and productivity using superlative index numbers. The Economic Journal, 92(365), 73-86. https://doi.org/10.2307/2232257

Dunning, J. H. (1979). Explaining changing patterns of international production: In defense of the eclectic theory. Oxford Bulletin of Economics and Statistics , 41 (4), 269-295. https://doi.org/10.1111/j.1468-0084.1979.mp41004003.x

Dunning, J. H. (1997). Alliance Capitalism and Global Business. London, England: Routledge. https://doi.org/10.4324/9780203279861

Evans, P., Pucik, V., \& Barsoux, J. L. (2010). The Global Challenge: Frameworks for International Human Resource Management. New York: McGraw-Hill.

Financial Times. (2017). Japan Inc's silence over Toshiba sends chill across Tokyo. Retrieved from Financial Times: https://www.ft.com/content/cabfe9d2-4c1f-11e7-919a-1e14ce4af89b

Gerlach, M. L. (1992). Alliance capitalism: The social organization of Japanese business. Berkley, CA: University of California Press.

Goold, M., \& Campbell, A. (1998). Desperately Seeking Synergy. Harvard Business Review, 76(5), 131-143.

Hall, E. T. (1976). Beyond culture. New York, NY: Anchor Books.

Harrison, J. S., Hitt, M. A., Hoskisson, R. E., \& Ireland, R. D. (2001). Resource complementarity in business combinations: Extending the logic to organizational alliances. Journal of Management 27(6), 679-690. https://doi.org/10.1177/014920630102700605

Hemmert, M., \& Jackson, K. (2016). Is there an East Asian model of MNC internationalization? A comparative analysis of Japanese and Korean firms. In Fitzgerald, R., \& Rowley, C. (Eds.), Internationalization patterns and the evolution of multinational companies: Comparing Japan, Korea, China and India (pp. 567-594). https://doi.org/10.1080/13602381.2016.1168617

Herbes, C. (2016). M\&A in Japan. In Haghirian, P. (Ed.), Routledge Handbook of Japanese Business and Management (pp. 75-88). Abingdon, England: Routledge.

Hymer, S. H. (1960). The international operations of national firms: A study of direct foreign investment. Cambridge, MA: MIT Press.

Ietto-Gillies, G. (2012). Transnational corporations and international production: concepts, theories and effects. Cheltenham: Edward Elgar Publishing.

Jackson, K. (2011). Talent Management. In Rowley, C., \& Jackson, K. (Eds.), Human resource management: The key concepts (pp. 206-213). Abingdon, England: Routledge.

Jackson, K. (2017). Structures of economic growth in Asia: lessons from Japan?. Abingdon: Routledge. Asia Pacific Business Review, 23(3). https://doi.org/10.1080/13602381.2016.1228239

Jackson, K., \& Matsumoto, S. (2016). Business networks in Japan: the impact of exposure to overseas markets. In Nolan, J., Rowley, C., \& Warner, M. (Eds.), Business Networks in East Asian Capitalisms: Enduring Trends, Emerging Patterns. Oxford: Chandos Publishing.

Kay, I. T., \& Shelton, M. (2000). The people problem in mergers. McKinsey Quarterly, 4, 29-37. 
Kurihara, T. (2006). Japanese corporate transition in time and space. New York: Palgrave Macmillan.

Maksimovic, V., Phillips, G., \& Prabhala, N. R. (2011). Post-merger restructuring and the boundaries of the firm. Journal of Financial Economics, 102(2), 317-343. https://doi.org/10.1016/j.jfineco.2011.05.013

Marks, M. L., \& Mirvis, P. H. (1998). Joining forces: Making one plus one equal three in mergers, Acquisitions and alliances. San Francisco: Jossey Bass.

Marsh, M., \& Kroll. (2008). M\&A beyond borders: Opportunities and risks. New York: Economist Intelligence Unit. Retrieved from www.mercer.com

Matsumoto, S. (2014). Japanese cross-border acquisitions, the causes of failure and success. Tokyo: Toyo Keizai.

Matsumoto, S. (2017, June 7). Create synergy by cross-border M\&A. Nikkei Newspaper, 28.

Matsumoto, S., \& Mishina, K. (2016). Premium for control and synergy. Journal of Economics and Business Administration, 213(3), 49-60.

Mintzberg, H. (2005). Managers not MBAs: A hard look at the soft practice of managing and management development. Oakland, CA: Berrett-Koehler Publishers.

Morgan, G. (1989). Creative organization theory: A resource book. London: SAGE Publications, Inc.

Nikkei. (2008). NSG decided to place Pilkington chief a president.

Nikkei. (2012). NSG president interview.

Nikkei Asian Review. (2015). Japanese companies' foreign acquisitions hit record 10tn Yen. Retrieved from https://asia.nikkei.com/Business/Deals/Japanese-companies-foreign-acquisitions-hit-record-10tn-yen

Nikkei Asian Review. (2017). Hitachi enters Europe elevator market with UK acquisition. Retrieved from https://asia.nikkei.com/Business/Deals/Hitachi-enters-Europe-elevator-market-with-UK-acquisition

Nissan Motor Corporation. (2016). Renault-Nissan Alliance delivers annual synergy target one full year ahead of

Nohria, N., \& Ghoshal, S. (1997). The Differentiated Network: Organizations Knowledge Flows in Multinational Corporations. San Francisco: Jossey-Bass.

NSG Group. (2006). NSG to proceed with recommended cash acquisition of Pilkington plc. NSG Group Announcement 2006. Retrieved from

http://www.nsg.com/en/media/announcements-2006/nsg-to-proceed-with-recommended-cash-acquisition-of -pilkington-plc

NSG Group. (2016). FY2016 Full-Year Results Announcement. NSG Group Announcement 2006. Retrieved from http://www.nsg.com/ /media/NSG/Site\%20Content/ir/Financial\%20Reports/AnnualResults2016_E02.ashx

NSG Group. (2016). Sale of Non-Current Assets and Recognition of Exceptional Gains. NSG Group Announcement 2006. Retrieved from http://www.nsg.com/en/media/announcements-2016/non-current-assets-and-exceptional gains

Porter, M. E. (1985). Competitive advantage: Creating and sustaining superior performance. New York: Free Press.

Porter, M. E. (1996). What is strategy?. Harvard Business Review, 74(6), 61-78

Pucik, V. (2008). Post-merger integration process in Japanese M\&A: The voices from the front-line. In C. L. Cooper \& S. Finkelstein (Ed.), Advances in Mergers and Acquisitions (Vol. 7, pp. 71-92). Cheltenham: Emerald Group Publishing Limited. https://doi.org/10.1016/s1479-361x(08)07005-1

Pucik, V., Björkman, I., Evans, P., \& Stahl, G. K. (2011). Human resource management in cross-border mergers and acquisitions. In A-W. Harzing \& A. H. Pennington (Eds.), International Human Resource Management (pp. 119-152). London, England: SAGE Publications, Inc.

Robson, C. (2002). Real world research: A resource for social scientists and practitioner-researchers. Oxford, England: Blackwell Publishers.

Saunders, M., Lewis, P., \& Thornhill, A. (2012). Research methods for business students. Harlow: Pearson. schedule. Retrieved from https://newsroom.nissan-global.com/releases/release-2072b950833a6bd77ebcd296d50023a3-160705-02-j?1 ang $=\mathrm{ja}-\mathrm{JP}$ 
Schein, E. H. (1992). Organizational culture and leadership. New York: Jossey-Bass.

Sirower, M. L. (1997). The synergy trap: How companies lose the acquisition game. New York: Free Press.

Sugiyama, S. (2013). Japan's Industrialization in the World Economy: 1859-1899 Export, Trade and Overseas Competition. London: Bloomsbury. https://doi.org/10.5040/9781472553416

Terjesen, S. (2014). Joint ventures: synergies and benefits. In S. Moeller (Ed.), The M\&A collection: themes in best practice (pp. 121-126). London: Bloomsbury Academic. https://doi.org/10.5040/9781472920355.0019

UNCTAD. (2017). Country Fact Sheets 2017. Retrieved from http://www.unctad.org

Watkins, M. (2007, May). Why DaimlerChrysler never got into gear. Harvard Business Review.

Yin, R. K. (2004). Case study methods. In Green, J. L., Camilli, G., Elmore, P. B., \& American Educational Research Association (Eds.), Handbook of complementary methods in education research. Mahwah, N.J: Lawrence Erlbaum Associates.

Yin, R. K. (2014). Case Study Research: Design and Methods. London: SAGE Publications, Inc.

Zaheer, A., Castañer, X., \& Souder, D. (2011). Synergy sources, target autonomy, and integration in acquisitions. Journal of Management, 39(3), 604-632. https://doi.org/10.1177/0149206311403152

\section{Copyrights}

Copyright for this article is retained by the author(s), with first publication rights granted to the journal.

This is an open-access article distributed under the terms and conditions of the Creative Commons Attribution license (http://creativecommons.org/licenses/by/4.0/). 